\title{
Four-in-one Management System for the Overseas Project Technical Support of Chinese Petroleum Company
}

\author{
S.Y. ZHOU \\ Petroleum Exploration and Production Institute, Sinopec, Beijing, China \\ Y. MA \\ SINOPEC International Petroleum Exploration and Production Corporation, Beijing, China \\ R.T. GUO \\ China University of Geoscience, Beijing, China
}

\begin{abstract}
In view of that the unclear overseas technical support mode, the low internationalized degree of management system and process, the ambiguous key node of quality control, and the weak multi-discipline and trans-department collaborative innovation ability in Chinese petroleum company nowadays, the establishment of "four-in-one" management system is extremely urgent. Based on the supporting demands of overseas program, this paper explores the three types of supporting modes, which lays the foundations for overseas supporting program management. The corresponding "hierarchy and classification" program management system and "two systems" operation management process are established, which form the operation monitoring management mechanism and the quality control management mechanism, and strengthen the executive power of system and process. The innovation framework is established, which enhances the support capability, and meet the overseas support demands.
\end{abstract}

KEYWORD: Overseas; Petroleum company; Technical support; Four-in-one management

\section{GENERAL INSTRUCTIONS}

Based on the development situation of global oil and gas, Chinese petroleum companies have formulated the overseas business development strategy since 2003. A batch of oil and gas exploration and development programs were obtained in short time, and the overseas strategy layout was basically completed. After more than ten years development by leaps and bounds, especially the recent six years, Chinese petroleum companies have gradually entered into the stage of pursuing value growth and optimizing layout structure, and the focus of work has shifted from acquisition of new programs to the operation results of existing programs and the improvement of development quality and efficiency. Nevertheless, there are some problems in Chinese petroleum company, including unclear overseas technical support mode, low internationalized degree of management system and process, ambiguous key node of quality control, and weak multi-discipline and trans-department collaborative innovation ability. So the establishment of technical support management system that is suitable for overseas development is urgent.

\section{THEORETICAL BASIS}

"Four-in-one" management system adopts PDCA (Plan-Do-Check-Action) management methods. PDCA cycle, also named Deming cycle[1,2], is the core idea of enterprise standardization construction and the criterion of standardizing enterprise behavior, which can make the management work run in cycle without a break. P (plan) means making work plan; D (do) means implementing established plan; C (check) means tracing and analyzing the implement condition; A (action) means taking measures to the planned results, and then turning into the next stage. The PDCA cycle is a process of continual improvement in program management, presenting stepwise upward trend. Some problems can be solved in each cycle, and then the program management can make advances in this process.

PDCA cycle has good applicability for overseas technical support. Taking the support demands of overseas program as core work, through the requirements analysis and overall planning for overseas program support, "four-in-one" management system includes the below steps. Firstly (P), determining the main support content and the support mode. Secondly (D), establishing suitable management system and process, building collaborative innovation architecture, organizing the implementation of support. Thirdly $(\mathrm{C})$, checking the 
applicability of support system by run dynamic control and quality control. Fourthly(A), adjusting supporting mode and operating mechanism in time, optimizing management system and process, realizing the continuous improvement of overseas technical support management, finally forming the PDCA closed-loop management.

\section{CONNOTATION}

According to the characteristics of overseas project operation and the needs of clients, we choose suitable support mode and process to establish overseas technical support "four-in-one" management system based on PDCA method.

"One", the core of this management system, means the proposed demands based on overseas project characteristics, which consistently run through the entire system. "Four" includes support mode, system process, operational control, and collaborative innovation.

According to the support demands, "four-in-one" management system explores the three kinds of support modes, which lays the foundation for overseas support management. The corresponding "classification" program management system and "two types of systems" operation management process are established, which form the operation monitoring management mechanism and the quality control management mechanism. The above measures strengthen the executive power of the management system and process. The innovation framework is established, which enhances the support capability, and meet the technical support demands of overseas project.

\section{MAIN MEASURES}

\subsection{Technical Support modes}

Together with support tasks, client needs, and support characteristics, the technical support of overseas exploration and development projects adopt three kinds of support modes.

\subsection{1 "Project" support mode}

"Project" support mode means organizing a relatively independent supporting institute to support a project omnibearingly. This mode has the characteristics of relatively complete professional configuration, fixed personnel, single working target, which guarantees that the staff can wholeheartedly devote to the project support. Leader of the support team can meet the support needs by personnel or other factors transferring.

Concerned with the programs needed for "omnibearing" support, client participates in or takes charge of the operating activities, such as production deployment, operation, construction. In the meantime, supporting company should provide longterm full support in terms of fundamental research, operation, reserve management, deployment decision, and solve the production problems in time. The support task has the characteristics of stability and protracted nature.

\subsection{2 "Function" support mode}

"Function" support mode means setting up corresponding research group according to the "standing subjects" of client, and providing longterm production operating support for client. It has the following characters, such as being convenient for accumulating experience and personnel training, forming professional advantages, playing a role in advisory functions.

Petroleum company establishes long-term subjects according to the needs of production operating decision, including assets operation, medium-long term plan, strategy research, etc. This decision support of "standing subjects" is provided by supporting company. The task has the characteristics of protracted nature, fixity, and persistence.

According to the "standing subjects" of client, supporting company sets up the Overseas Planning Institute, the Project Evaluation Institute, the Information Center, and all the institutes are composed of corresponding research groups, providing long-term operating decision support service.

\subsection{3 "Matrix" support mode}

"Matrix" support mode means a composite structure organization formed by two crossbar systems. The longitudinal bar is function systems; while the horizontal bar is program systems for accomplishing some special tasks. It strengthens the horizontal connections, and increases the management flexibility. This mode not only benefit to forming professional technical centers which are helpful to accumulate experience, but also can make full use of the professional equipment and personnel. It also has the characteristics of relatively high mobility and flexibility, which can be established or dismissed with the program launch or closure.

"Matrix" support mode is suitable for the projects whose supporting tasks are unstable. For solving the difficulties and hot issues in production, client sets up corresponding research subjects. 
4.2 "Hierarchy and classification" management system and "two systems" control flow

\subsection{1 "Hierarchy and classification" management system}

Technical support subjects should employ "classification" management system; while the quality control should employ "classification" management system, which can not only standardize subject management process, but also strengthen subject process and quality control.

(1) Subject "classification" management

According to the characters of supporting task, the overseas scientific research and production subjects can be divided into "production type" and "research-production type" to manage.

(1) "Production type" subject means the "short, adaptable, and fast" subjects, which are established for solving the production problems timely, based on the production difficulties and hot issues.

Client usually does not organize evaluation, and has no demand for format reports. The research results are confirmed in the form of communication, and applied to production in time.

The management of technical subject start-up, acceptance check is organized by supporting departments.

(2) "Research-production type" subject means providing decision support for fundamental research, strategy research, exploration and development tracing deployment, reservoir management, according to the research subjects established for solving the technical problems in production process.

Client usually demands that the supporting company should submit format reports, and organize evaluation.

The management of supporting subject start-up, acceptance check is organized by the institute administrative department.

(2) Quality "classification" management

The management of supporting subjects quality employs the system of chief reviewer examination.

Two-stage quality control is employed for the "production type" subjects, and the signature of chief reviewer is taken as the evidence of client's examination.

Three-stage quality control is employed for the "research-production type" subjects, and signature of the third stage examination group leader is taken as the evidence of client's examination.

\subsubsection{The quality control process of "Approval system" and "Audit system"}

(1) "Approval system"

"Production type" subjects have the characteristics of strong guidance, high efficiency, therefore will be adopted two-stage quality control, while in the third stage quality control, "Approval system" is used, and the administrative department confirms the content of communication. In case of important production plan or the quality control in first two stages existing uncertainty, subject group applies to the administrative department for organizing institute experts to review the subject results.

(2) "Audit system"

Quality control of "Research-production type" subjects adopt "Audit system". Before submitting to client, technical subject start-up and acceptance check should be checked by three-stage quality control, including subject group, scientific research department. Only passed the review of institute academic board, the subject reports can be submitted to client.

\subsection{Two operation control systems}

\subsection{1 "Chart-table-volume" dynamic monitoring mechanism}

The emphasis of "four-in-one" management system is node and process control. "Subject progress Gantt chart" , "subject operating dynamic table", and "subject data volume" should be established. Though "chart-table-volume", subject group can grasp the subject operational dynamics, and strengthen process management, which can enhance the standardization, informatization, and refinement of management.

(1) Subject progress Gantt chart

For grasping the operational dynamics and urging the subject group to run subject according to the schedule, the subject progress Gantt chart should be made. Based on the category of subject, the corresponding review and quality control should be conducted timely.

(2) Subject progress dynamic table

The overseas technical support subjects have characteristics of complex contract form, multi-node control, research funding being payed with research progress. Therefore, making out the "overseas technical support subjects operational analysis table", including three categories of basic information, operational control node, and business management information, can realize the seamless connection management of the whole process with high work efficiency.

(3) Subject data volume

The subject data volume should be compiled by year, including the information of establishment, intermediate inspection, final check, etc.

\subsection{2 "Meeting-feedback-check" quality control system}

Through overseas technical support operational meeting, trans-department coordination, client feedback, and three grade quality control, the 
"meeting-feedback-check" quality control system can be established, which can enhance the effectiveness of overseas supporting subject.

(1) Two meetings

Overseas technical support has characteristics of multi-discipline and trans-department cooperation. Therefore, the communication and coordination mechanism should be established. Through the operational regular meeting and the trans-department coordination meetings, supporting company can control the subjects progress and the key node, solve the problems in supporting process, and deploy stage task. Strengthening multi-discipline and transdepartment cooperation can improve subject research quality.

(2) Client feedback

Supporting company conducts quality feedback from client in order to know the comments and suggestions for technical supporting level and capability, through the contract task completion situation, quality and application effect, service consciousness, etc. Finally, supporting company writes client feedback report, urges relative departments to set up rectification measures in order to enhance the service consciousness and supporting level.

(3) Three-grade quality control

According to the "hierarchy and classification" management process, supporting company should pay close attention to the milestone of every subjects, and conduct strictly quality control for research achievements. The base of three-stage quality control is self-assessment of program group (the first stage quality control); the key of which is inspection of scientific research department (the second stage quality control); and the enhancement of which is review of institute professional committee (the third stage quality control). Through three-stage quality control, the supporting company can conduct quality control for the contract task completion situation, research thinking and technical route, achievement quality promotion situation, and ensure the supporting effect.

\subsection{Establishing cooperative innovation framework}

Supporting company can establish cooperative innovation system, collaborative research mechanism, and international communication platform, which can create conditions for "multidiscipline communication and study", "transdepartment collaboration", and "multi-level technical exchange", promote collaborative innovation capability, and enhance the technical support level.

\subsubsection{Cooperative innovation system}

The non-linear, multi-role, networked, open cooperative innovation system should be established. The bases of this system are transdepartment and multi-discipline cooperation within institute, and trans-institute cooperation[3,4]. Original innovation, integrated innovation, and imitation innovation can expand development space, enhance innovation capability, and provide development power for creating first-class research institute[5-7].

\subsubsection{Collaborative research mechanism}

(1) Technical seminar

Technical seminar mainly includes follow aspects. Firstly, organize exploration and development dynamic analysis meeting, subject progess meeting, technical bottleneck analysis and solution meeting regularly, in order to promote mutual learning in the same discipline, integration in different disciplines, and create conditions for collaborative innovation. Secondly, organize technical exchanges with university and special technical companies, in order to strengthen technical training and innovation foundation. Thirdly, organize relative experts meeting for the hot issues in technical support, in order to establish technical exchange platform, improving academic atmosphere, and realizing achievement and information sharing.

(2) Joint support

Joint support means that supporting companies of overseas project, taking specific subject as bounding point, carries out multi-discipline and transdepartment joint support, strengthens multidiscipline integration, and promotes collaborative innovation.

(3) Coordination regular meeting

Through research and production supporting regular meeting, and trans-department supporting regular meeting, supporting company can grasp the subject progress and staged achievements, solve the problems appeared in joint support, and create favorable conditions for collaborative innovation.

\subsubsection{Establishing international communication platform}

(1) Organizing scientific research departments to declare international conference attending plans in beginning of the year. Supporting company chooses delegations with purpose, plan and hierarchy, which can promote forward-looking research study, and enhance technical level.

(2) Organizing "international communication achievements report conference" in batches. Supporting company invites delegations attended international conference to exchange their 
achievements, which can expand the benefit of international conference further.

(3) Choosing excellent international technical companies and introducing advanced technology, including reservoir, physical geography, enhancing oil recovery, fluid and hydrocarbon detection, the evaluation of seal and preservation, etc.

(4) Strengthening technical exchanges with overseas program companies, promoting the combination of rear support and on-site production, strengthening transformation effect of research results.

(5) Strengthening the joint research with overseas project cooperative companies, taking the difficulties in production as the breakthrough point, achieving mutual promotion and enhancement.

\section{CONCLUSION}

Based on the characters of overseas project operation and the demands of client, "four-in-one" management system employs PDCA cycle method, and chooses suitable supporting mode as the framework. Taking optimized system process as tools, together with the strict quality control and the purpose of sustainable collaborative innovation, this manage system can provide new ideas for the further development of scientific research innovation in Chinese petroleum company's overseas technical support.

\section{REFERENCES}

[1] Liu Yang. Design and Implementation of Project Management System Based on PDCA Cycle Model, Software Industry and Engineering, 2013, 3: 24-28

[2] Zhou Lihua. Application Study on Modern Project Management in Maintenance of Hydropower Units, Shanxi Science and Technology, 2014, 1: 28-31

[3] Baptism R. \& Swann G.M.P.Do Firms in Clusters Innovate more? Research Policy. 1998, 27: 525-540

[4] Thomas Fischer. Collaborative Innovationin Ubiquitous Systems. International manufacturing, 2007, (18)

[5] Veronica Serrano \& Thomas Fischer. Collaborative Innovationin Ubiquitous Systems. International manufacturing, 2007, (18)

[6] Cooke, Sehienstoek. Structural Competitiveness mid Learning Region. Enterprise and Innovation Management Studies. 2000, 1(3): 265-280

[7] Bonaccorsi A. \& Piccalugadu A. A Theoretical Framework for the Evaluation of University - industry Relationships. R\& D Management, 1994, (3). 